\title{
Clinical and functional evaluation of anterior cruciate ligament tears after anterior cruciate ligament reconstruction
}

\author{
Thakur R. ${ }^{1}$, Samal N. ${ }^{2}$, Gawande V. ${ }^{3}$, Kochhal N. ${ }^{4}$ \\ ${ }^{1}$ Dr. Rahul Thakur, Resident, ${ }^{2}$ Dr. Nitin Samal, Professor, ${ }^{3}$ Dr. Vasant Gawande, Associate Professor, ${ }^{4}$ Dr. Niharika \\ Kochhal, Final Year MBBS Student, all authors are affiliated with Department of Orthopedics, Jawaharlal Nehru \\ Medical College, Sawangi, Wardha, Maharashtra, India.
}

Corresponding Author: Dr. Rahul Thakur, Resident, Department of Orthopedics, Jawaharlal Nehru Medical College, Sawangi, Wardha, Maharashtra, India. E-mail: drrahul.thakur03@gmail.com

\begin{abstract}
Introduction: There have been many studies on ACL reconstruction and its outcome. In our study, we used single bundle reconstruction as the technique for Indian rural population as it is one of the most reliable technique for ACL reconstruction after the injury. Aim: To study the pattern of clinical and functional evaluation of anterior cruciate ligament injury after anterior cruciate ligament reconstruction. Objectives: (1) To assess the pattern of anterior cruciate ligament injury and instability caused by it (2) To study the clinical \& functional outcome of ACL in arthroscopic ACL reconstruction in patient with ACL tear. Results: The outcome scores themselves, at the end of 12 months follow up were significantly better in operated patient. We found better knee function and patients were able to do their daily activity normal (as before the injury). Results of our study were compared with other study done worldwide and we also found better results and better life style in post operated patient of ACL. The study concludes that, Arthroscopic ACLR is a good choice for ACL reconstruction and HS grafts were a good choice for reconstruction along with endobutton and screw. This study shows that ACL is one of most important ligament in the knee joint and must be taken care of for a better knee function. Conclusion: The reconstruction of anterior cruciate ligament tears with hamstring tendon grafts gives a very good clinical and functional outcome.
\end{abstract}

Keywords: ACLR, Anterior cruciate ligament reconstruction, Sports injury, Arthroscopy

\section{Introduction}

Knee is the largest joint in the human body with a very complex anatomy (pivotal hinge joint). The ligaments surrounding the knee joint offer stability by limiting movements, together with several menisci and bursae, shield the articular cartilage and capsule. ACL originates from the medial and anterior aspect of the tibial plateau and runs superiorly, laterally and posteriorly towards its insertion on the lateral femoral condyle. The anterior cruciate ligament is composed of the anteromedial and posterolateral bundles $[1,2]$.

Together, these bundles provide approximately $85 \%$ of total restraining force of anterior translation, $[3,4]$. Since the knee supports nearly the whole weight of the body, it is vulnerable to both acute injury and chronic repetitive trauma leading to the development of osteoarthritis.

Manuscript Received: $1^{\text {st }}$ February 2019

Reviewed: $8^{\text {th }}$ February 2019

Author Corrected: $13^{\text {th }}$ February 2019

Accepted for Publication: $18^{\text {th }}$ February 2019
ACL is an important ligament for the movement of knee joint. ACL injury commonly causes knee instability and subsequently causes more stress to other knee ligaments [5]. ACL failure has been linked to heavy or stiff-legged landing, as well as twisting or turning the knee while landing, especially when the knee is in the valgus position.

Women in sports are more prone to ACL injuries than men. The discrepancy has been attributed to differences between the sexes in anatomy, general muscular strength, reaction time of muscle contraction and coordination, and training techniques. Study suggests hormone-induced changes in muscle tension associated with menstrual cycles may also be an important factor [6]. Recent research also suggests that there may be a gene variant that increases the risk of injury [7]. ACL injury has an annual incidence of more than 200,000 cases with 100,000 amongst these knees are reconstructed annually. 


\section{Original Research Article}

The majority of ACL injuries (70\%) occur while playing agility sports and most often reported sports are basketball, soccer, skiing, and football. An estimated $70 \%$ of ACL injuries are sustained through non-contact mechanisms, while the remaining $30 \%$ result from direct contact $[8,9]$.

The Pivot-shift test, Anterior drawer test and the Lachman test are used during the clinical examination of suspected ACL injury and IKDC scoring, Cincinnati scoring \& Lysholm score as functional scoring system for patients. KT-1000/2000 can assist in the diagnosis but are more effective in evaluating patients with chronic anterior cruciate ligament disruption when pain and associated muscle guarding are absent $[10,11,12]$.

Surgery remains the treatment of choice in almost all athletes who want to remain active. Some problems that have resulted in failed ACL reconstruction, particularly omitting reconstruction of the PL bundle [13,14]. Long-term studies have shown that there is a significant increase in the rate of damage to menisci and articular cartilage associated with delayed reconstruction $[15,16]$.

Generally, about one-third of patients who are selected as suitable for conservative treatment are able to complete the therapy regimen without the need for surgical intervention $[17,18]$.

However, patients with high level of sports activity show poor results after conservative treatment of ACL ruptures $[15,17,19]$. No ideal graft site for ACL reconstruction exists; they all have advantages and disadvantages.

Patellar tendon grafts are still considered the historical "gold standard" for knee stability by surgeons [20]. Modern fixation methods of hamstrings avoid graft slippage, producing outcomes that are same in the terms of knee stability with easier rehabilitation, less anterior knee pain and less joint stiffness [21].

Single-bundle ACL reconstruction has been a standard option to treat symptomatic ACL-deficient knees. Single-bundle reconstruction with the bone-patellar tendon-bone (BTB) or hamstring tendon graft did not show any significant effects on the rotatory instability during walking or more active activities [22].

The aim of this study is to assess the benefit of arthroscopic assisted ACL reconstruction using autologus hamstring grafts in term of clinical and functional outcome.
We have compared the functional outcome in patient with ACL tear before surgery and after surgery at regular intervals. For evaluation of functional outcome, the IKDC score [23], Lysholm score [24, 25] and Modified Cincinnati score [26] were used. For clinical outcomes special test like Lachman test, pivot shifting test were used. We have used standardized procedures and the same kind of implants in all patients.

\section{Materials and Methods}

Type of Study- Prospective study

Study Setting- Department of Orthopedics of tertiary care hospital.

Sampling Methods- All adult patients who met the inclusion criteria were included in the study. Clinical history of each patient was recorded as per the Performa. Clinical details including risk factors, antibiotics given, complete haemogram and other biochemical parameters were also recorded.

Statistical Methods-The tabulation and cross tabulation will be done. Results will be expressed in percentage. Data entry and analysis will be done using SPSS software for windows version 17.0 and Gratan Pad prism 6.0 version. Pearson's Chi-square test at 95\% confidence limit and Fisher's exact test will be used for calculating

Ethical Permission \& Consideration- Approval of institutional ethics committee was taken.

Scoring Systems- IKDC score, Lysholm score, Modified Cincinnati score.

Surgical Procedures- Single bundle ACLR.

Study Size- A total of 50 patients were included in the study, allocated to single bundle reconstruction technique.

Subjects- Patients attending Acharya Vinoba Bhave Rural Hospital for Knee Injury.

Sample Size-This Being A Prospective Study included all the fresh cases of anterior cruciate ligament injury. $(\mathrm{N}=50)$

Place of Study- Department of Orthopaedics, Acharya Vinoba Bhave Rural Hospital, Sawangi (Meghe) Wardha.

Duration of Study: - 2 years (2015-2017) 


\section{Inclusion criteria}

1. All the patients between 18-60 years of age admitted in our hospital for Anterior Cruciate Ligament injuries.

2. All the patients between 18-60 years of age who underwent Anterior Cruciate Ligament repair.

\section{Original Research Article}

\section{Exclusion criteria}

1.Patients with active knee joint infection / additional bony injury

2. Patients not willing for any treatment and follow up

3. Patients who were not willing to give consent for surgery / rehabilitation after surgery

\section{Results}

Patient Details- A total of 50 patients were recruited under this study. Final data collection was completed for all these 50 patients. All the patients were followed up regularly as per the stipulated timings of the one years.

Descriptive Patient Statistics- Mean age of the patients in ACLR group was 29.33 (18-50 years) years with standard deviation \pm 9.98 . Minimum age in study groups was 18 years and maximum age was 50 years Out of the total 50 patients, $46(92 \%)$ patients were male and only $4(8 \%)$ were female.

Table-1: Demographic distribution of patents

\begin{tabular}{|c|c|c|}
\hline Age Distribution & Female & Male \\
\hline $20-24$ & 2 & 7 \\
\hline $25-29$ & 1 & 13 \\
\hline $30-34$ & 1 & 6 \\
\hline $35-39$ & & 2 \\
\hline $40-44$ & $\mathbf{4}$ & $\mathbf{4 6}$ \\
\hline
\end{tabular}

Mechanism of the injury-The most frequent mechanism was found to be Sports activities ( $\mathrm{n}=22,44 \%)$ followed by Road traffic accidents $(n=13,26 \%)$ and then miscellaneous causes like fall from height, twisting injury while going downstairs, hit by animal, slip and fall ( $\mathrm{n}=15,30 \%)$.

Table-2: Mode of Injury.

\begin{tabular}{|c|c|c|}
\hline Mode of injury & No of patients & Percentage (\%) \\
\hline Sports & 22 & 44 \\
\hline Road Traffic Accidents & 13 & 26 \\
\hline $\begin{array}{l}\text { Miscellaneous(Fall from height, Twisting Injury, Slip } \\
\text { and Fall, Hit by animal) }\end{array}$ & 15 & 30 \\
\hline Total & 50 & 100 \\
\hline
\end{tabular}

Table-3: Distribution of patients according to associated injury

\begin{tabular}{|c|c|c|}
\hline Associated injury & No of patients & Percentage (\%) \\
\hline Lateral Meniscus & 15 & 30 \\
\hline Medial Meniscus & 10 & 20 \\
\hline LM+MM & 2 & 4 \\
\hline No Meniscal Injury & 23 & 46 \\
\hline Total & $\mathbf{5 0}$ & $\mathbf{1 0 0}$ \\
\hline
\end{tabular}

Associated Meniscal Injuries- Out of the 50 patients, 15(30\%) patients had lateral meniscal Injury, 10(20\%) patients had medial meniscal Injury, and 2(4\%) patients had both lateral and medial meniscal injury 23(46\%) patients had no meniscal injury. 


\section{Original Research Article}

Table-4: Distribution of patients according to outcome.

\begin{tabular}{|c|c|}
\hline Rating & Number of patients \\
\hline Poor & 2 \\
\hline Fair & 8 \\
\hline Good & 15 \\
\hline Excellent & 25 \\
\hline Total & $\mathbf{5 0}$ \\
\hline
\end{tabular}

Out of 50 patients we had 2 patients with poor results due to involvement of associated lateral and medial meniscal injuries. 8 patients had fair clinical outcome due to noncompliance with post-operative physiotherapy. 15 were with good results and 25 patients had an excellent result which we assessed by clinical assessment of 3 important clinical tests mentioned above. Similar results were obtained on functional evaluation also as mentioned by the different scoring methods used in this study.

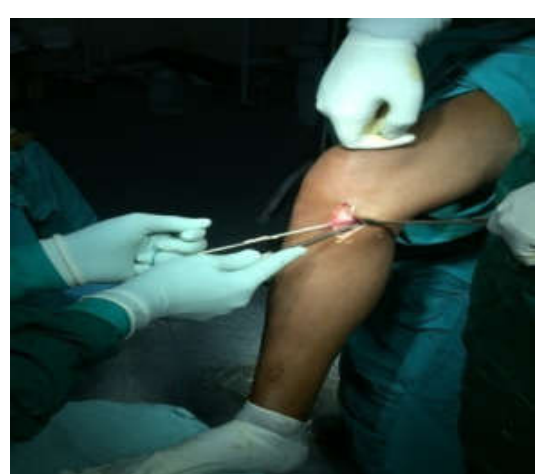

Fig.-1: Graft harvesting.

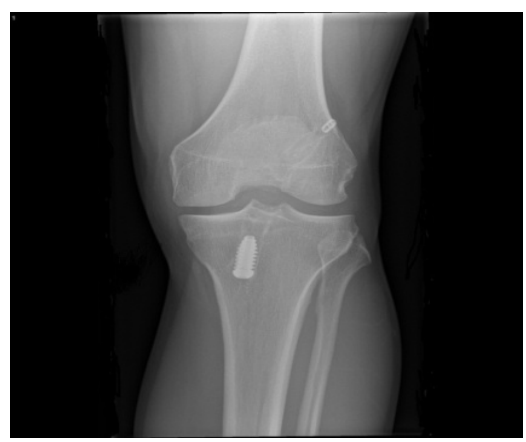

Fig-3: post-operative $X-$ ray A-P view

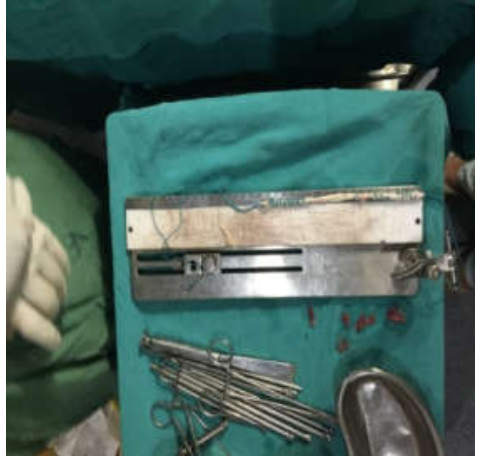

Fig.-2: prepared hamstring free graft arthroscopic view of ACL stump (tibial side)

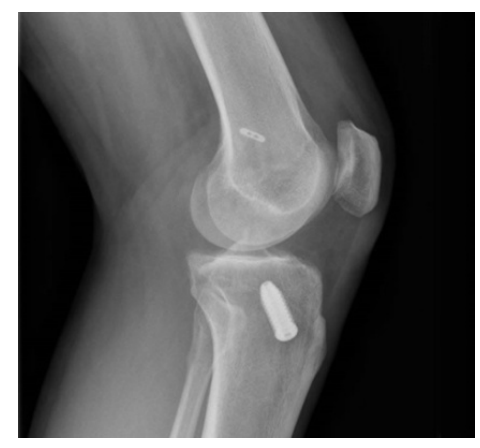

Fig-4: Post-operative X-ray lateral view

\section{Discussion}

Many different techniques have been suggested for ACLR using different tunnel positions, fixation systems, and types of graft. A number of studies have been conducted to compare postoperative stability and function after anatomic single bundle and double bundle anterior cruciate ligament reconstruction.

Table-5: Clinical outcome of patients evaluated by the lachman test and anterior drawer tests.

\begin{tabular}{|c|c|c|}
\hline Clinical Outcome & Results in numbers & Results in \% \\
\hline Poor & $2 / 50$ & $4 \%$ \\
\hline Fair & $8 / 50$ & $16 \%$ \\
\hline Good & $15 / 50$ & $30 \%$ \\
\hline Excellent & $25 / 50$ & $50 \%$ \\
\hline
\end{tabular}




\section{Original Research Article}

We undertook a study in which we followed up, evaluated and recorded the function of 50 patients. All of which underwent arthroscopic ACLR. The patients were evaluated pre-operatively, and post-operatively at pre determined time intervals (3 months, 6 months and 12 months) post-operatively. Evaluation was done using three accepted scoring systems for knee function- 2000 IKDC Subjective Knee Evaluation Score, Lysholm Score, Modified Cincinnati Score. Ligament stability was clinically examined by the Lachman test, Pivot-shift test, Anterior drawer test and Pivot shift test. Laxity was graded relative to the uninjured knee according to the IKDC guidelines.

After statistical analysis of the data, a set of results were obtained. Most of our data matched with the literature concerning the outcomes of both the procedures which have been published. Conversely, many differences were found, both in patient profiles and the outcomes. Some of these pertain to socioeconomic differences between the study populations in our study and those conducted abroad. Meanwhile, some parameters differ, probably because of the difference in the kind of physical activity the populations generally engage in.

The mean age of the patients in our ACLR group was 29-33 (18-50 years) with standard deviation \pm 9.98 . Minimum age in study groups was 18 years and maximum age was 50 years. This aspect of our data matches the overall published literature as various authors have noted that the problem occurs in young and athletic, physically active individuals. In

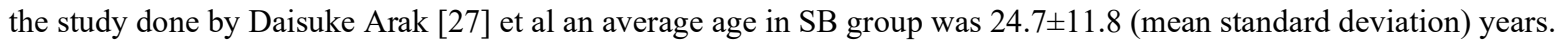
In a study by Alberto Gobbi [28] et al, the mean age of patients at surgery in SB group was 31.9 \pm 1.9 years. Eun Kyoo Song [29] et al found that an average age of patients SB group was 30.3 years (range, 17-50). N. Adachi [30] et al found that the average age of patients in SB group was 29.5 (14 to 49). No studies in literature have so far commented about the effect of age on the functional outcome.

As for the sex distribution, out of the 50 patients in our study, 46 patients were male, and 4 patient were female. Overall amongst the various studies published, the number of male patients has consistently been far larger than the female patients [31-35]. This predisposition is probably due to the fact frequently participate in sports activities and occupations involving vigorous activities and risks of fall and twisting injuries.

In this study, the number of female patients $(n=4)$, made it impossible to perform any valid analysis on whether sex is a significant factor influencing the outcome. The scenario is similar in several other studies. However, even studies where the number of female patients could probably have allowed analysis, have not mentioned any association with any outcome parameters with the sex.

In our study amongst the 50 patients, $35(70 \%)$ patients had ACL tear on the right side, $15(30 \%)$ patients had the injury on the left side. In a study by Alberto Gobbi et al, in SB group, 18 patients had the injury in left knee and 12 patients had the injury in right knee. In a study by R. Siebold [36] et al, 17 patients had injury in right knee and 11 patients had the injury in left knee in a SB group. No studies in literature have so far commented about the effect of laterality on the functional outcome.

The average time from injury to reconstruction was 7.01 $\pm 5.99(0.27$ months- 24 month). The studies in the literature have reported the similar findings. In a study by Eun Kyoo Song [29] et al the average time from injury to reconstruction in the double-bundle group was 8.3 months (range, 1-26). The average time from injury to reconstruction in the single-bundle group was 7.6 months (range, 2-20). In a study held by Eiji Kondo [29] et al, average time was 12 months in SB group and 16 months in DB group. In a study by N. Adachi [37] et al the average time was 27 months in SB group. No studies in literature have so far commented about the effect of the average time from injury to reconstruction on the functional outcome.

The results as per the various scoring systems are the most important aspect of our study. Comparison with the published data has shown some similarities and some differences between our study results and those done abroad. The studies published in the literature do not give the specific scores at the intervening time intervals and straight away state the scores at the end of the study. This means we can make a comparison only between our final results and theirs, although there is a large discrepancy between the duration of follow up in our study and theirs. The scores at the intermediate follow ups are not mentioned in these other studies, so comparisons on whether the course of our patients" progress matches theirs are difficult. 


\section{Original Research Article}

Alberto Gobbi [30] et al found that in SB group, the IKDC score in preoperative period was $41.5 \pm 4.21$ (mean \pm SEM) and that in post-operative period at 3 year follow up was $89.4 \pm 1.47$ (mean \pm SEM) with a p-value suggestive of significant improvement. In the same study the Lysholm score in preoperative period was $42.4 \pm 3.30$ (mean $\pm \mathrm{SEM}$ ) and that in post-operative period at 3 year follow. Another study done by R. Siebold [32] et al shows that in SB group, the IKDC score in post-operative period was \pm 15.1 and the Cincinnati knee score in the post-operative period was 81.8 .

In a study done by Takeshi Muneta [38] et al the total Lysholm knee scale score was 93 in the post-operative period at 2 year in a SB group. In this study the IKDC score in the preoperative period, at $3^{\text {rd }}$ month, $6^{\text {th }}$ month and $12^{\text {th }}$ month, was $46.38,51.16,54.64,61.20$ respectively which was suggestive of improvement in the functional status with time.

The Lysholm score in SB group also has increasing trend, the average score in the preoperative period, at $3^{\text {rd }}$ month, $6^{\text {th }}$ month and $12^{\text {th }}$ month was $65.14,72.04,74.72,78.90$ respectively which was suggestive of improvement in the functional status of the patients with time.

Similar trend was observed in Modified Cincinnati Score, the average score in the preoperative period, at $3^{\text {rd }}$ month, $6^{\text {th }}$ month and $12^{\text {th }}$ month, was $52.26,61.42,63.98,67.2 .35$, respectively which was suggestive of improvement in the functional status of the patients with time.

Another important analysis is of laxity testing by Lachman and Pivot shift test. In a study by Eun Kyoo Song [29] et al, in SB group were such that, in pre-operative period, out of 20 patients, 4 had grade 2 laxity and 16 patients had grade 3 laxity and in post-operative period at 2 year follow up, 12 patients had grade 0 laxity, 5 patients had grade 1 laxity, 2 had grade 3 laxity and no pt had grade 4 laxity was suggestive of non-significant difference. In the same study, Pivot shift grading was used for measuring laxity. The difference was found to be statistically insignificant.

\section{Conclusion}

Majority of the population affected in this study belonged to the group of sports injuries which is a major cause of ACL tear. This study showed that single bundle ACLR is a must needed operative procedure for a better functional outcome of knee and to perform daily activities of life. This concludes that, Arthroscopic ACL reconstruction with Hamstring grafts was a good choice for good to excellent outcomes.

Conflict of interest: None declared.

Funding: Nil, Permission from IRB: Yes

\section{References}

1. Girgis FG, Marshall JL, Monajem A. The cruciate ligaments of the knee joint: anatomical, functional and experimental analysis. Clin Orthop Relat Res. 1975 JanFeb;(106):216-31 .

2. Petersen W, Zantop T. Anatomy of the anterior cruciate ligament with regard to its two bundles: Clin Orthop Relat Res. 2007 Jan;454:35-47.

3. Kisner C, Colby LA. The knee. Therapeutic exercise: Foundations and techniques, 4th ed. Philadelphia: F.A. Davis Company;2002.

4. Magee DJ. Orthopaedic physical assessment, 4th ed. Philadelphia: Saunders; 2002
5. Levy DB, Dickey-White HI. Knee Injury, Soft Tissue, e Medicine, Dec 15, 2009.

6. Catalyst: Weak at the Knees - ABCScience.

7. Posthumus M, September AV, O'Cuinneagain D, van der Merwe W, Schwellnus MP, Collins M (2009) The COL5A1 gene is associated with increased risk of anterior cruciate ligament ruptures in female participants. American Journal of Sports Medicine, 2009 Nov; 37(11):2234-40. doi: 10.1177/ 0363546509338266. Epub 2009 Aug 4.

8. American Academy of Orthopaedic Surgeons, July 2007, Anterior Cruciate Ligament Injury: Surgical Considerations, http://orthoinfo.aaos.org/ topic.cfm? topic $=$ A00297\# A00297_R4_anchor (July 11, 2008).

9. Griffin LY1, Agel J, Albohm MJ, Arendt EA, Dick RW, Garrett WE, Garrick JG, Hewett TE, Huston L, Ireland ML, Johnson RJ, Kibler WB, Lephart S, Lewis JL, Lindenfeld TN, Mandelbaum BR, Marchak P, Teitz CC, Wojtys EM Noncontact Anterior Cruciate Ligament Injuries: Risk Factors and Prevention Strategies. Journal of the American Academy of Orthopaedic Surgeons. 2000 May-Jun; 8 (3): $141-50$ 


\section{Original Research Article}

10. The Reliability, Validity, and Responsiveness of the Lysholm Score and Tegner Activity Scale for Anterior Cruciate Ligament Injuries of the KneeKaren K. Briggs, MPH, Jack Lysholm, Am J Sports Med. 2009 May; 37 (5): 890-7. doi: 10.1177/0363546508330143. Epub 2009 Mar 4.

11. Noyes FR, Barber SD, Mooar LA. A rationale for assessing sports activity levels and limitations in knee disorders. Clin Orthop Relat Res. 1989 Sep;(246): 238-49.

12. Irrang JJ, Ho H, Harner $\mathrm{CD}, \mathrm{Fu} F H$. Use of the International Knee Documentation Committee Guidelines to assess outcome following anterior cruciate ligament reconstruction. Knee Surg Sports Traumatol Arthrosc. 1998;6(2):107-14.

13. Odensten M, Gillquist J. Functional anatomy of the anterior cruciate ligament and a rationale for reconstruction. J Bone Joint Surg Am. 1985 Feb;67 (2): 257-62

14. Georgoulis AD, Pappa L, Moebius U, MalamouMitsi V, Pappa S, Papageorgiou CO, Agnantis NJ, Soucacos PN. The presence of proprioceptive mechanoreceptors in the remnants of the ruptured ACL as a possible source of re- innervation of the ACL autograft. Knee Surg Sports Traumatol Arthrosc. 2001 Nov; 9 (6):364-8. Epub 2001 Sep 7.

15. Li G, DeFrate LE, Sun G, et al. In vivo elongation of the anterior cruciate ligament and posterior cruciate ligament during knee flexion. Am J Sports Med. 2004;32:1415-1420.

16. Sakane M, Fox RJ, Woo SL-Y Livesay GA, Li G, $\mathrm{Fu}$ FH.. In situ forces in the anterior cruciate ligament and its bundles in response to anterior tibial loads. J Orthop Res.1997;15:285-293.

17. Prodromos CC, Fu FH, Howell SM, Johnson DH, Lawhorn K.. Controversies in soft-tissue anterior cruciate ligament reconstruction: grafts, bundles, tunnels, fixation, and harvest. J Am Acad Orthop Surg. 2008;16:376-384.

18. Noyes FR, Mooar PA, Matthew DS, Butler DL. The symptomatic anterior cruciate-deficient knee, part I. J Bone Joint Surg Am.1983;65:154-162

19. Recht MP, Piraino DW, Cohen MA, Parker RD, Bergfeld JA. Localized anterior arthrofibrosis (cyclops lesion) after reconstruction of the anterior cruciate ligament: MR imaging findings. Am J Roentgenol. 1995; 165:383-385.

20. Biau DJ, Katsahian S, Kartus J, Harilainen A, Feller JA, Sajovic M, Ejerhed L (December 2009). "Patellar Tendon Versus Hamstring Tendon Autografts for Reconstructing the Anterior Cruciate Ligament". Am J Sports Med 37 (12):2470-8

21.http://www.aclsurgery.us/patellar-vs-hamstring, nov-ember 15,2008

22. Zaricznyj B. Reconstruction of the anterior cruciate ligament of the knee using a doubled tendon graft. Clin Orthop Relat Res.1987;220:162-175.

23. Irrang JJ, Ho H, Harner CD, Fu FH. Use of the International Knee Documentation Committee Guidelines to assess outcome following anterior cruciate ligament reconstruction. Knee Sports Traumatol Arthrosc 1998; 6: 107-14.

24. Lysholm J, Gillquist J. Evaluation of knee ligament surgery results with special emphasis on use of a scoring scale. Am J Sports Med. 1982 May-Jun;10 (3): 150-4.

25. Tegner Y, Lysholm J. Rating systems in the evaluation of knee ligament injuries. Clin Orthop Relat Res. 1985 Sep;(198):43-9.

26. Noyes FR, Barber SD, Mooar LA. A rationale for assessing sports activity levels and limitations in knee disorders. Clin Orthop Relat Res. 1989 Sep; (246): 238-49.

27. Daisuke Araki, Ryosuke Kuroda, Seiji Kubo, Norifumi Fujita, Katsumasa Tei, Koji Nishimoto, Yuichi Hoshino, Takehiko Matsushita, Tomoyuki Matsumoto, Koki Nag.amune, Masahiro Kurosaka. A prospective randomised study of anatomical singlebundle versus double-bundle anterior cruciate ligament reconstruction: quantitative evaluation using an electromagnetic measurement system, International Orthopaedics (SICOT, 2011) March 2011, Volume 35, Issue 3, pp 439-446.

28. Gobbi A Tuy B, Mahajan S, Panuncialman I.Quadrupled bone-semitendinosus anterior cruciate ligament reconstruction: a clinical investigation in a group of athletes. Arthroscopy. 2003 Sep;19(7):691-9, Volume 19, Issue 7, September 2003, Pages 691-699, doi.org/10.1016/S0749-8063(03)00685-6 


\section{Original Research Article}

29. Eun Kyoo Song, Luke S. Oh, Thomas J. Gill, Guoan Li, Hemanth R. Gadikota and Jong Keun Seon Prospective Comparative Study of Anterior Cruciate Ligament Reconstruction Using the Double-Bundle and Single-Bundle Techniques Am J Sports Med 2009 37: 1705. Volume: 37 issue: 9, page(s): 1705-1711

30. Adachi N, Ochi M, Uchio Y, Iwasa J, Kuriwaka M, Ito Y. Reconstruction of the anterior cruciate ligament: single- versus double-bundle multistranded hamstring tendons, The Bone \& Joint Journal 86(4):515-20 • June 2004, DOI: 10.1302/0301-620X.86B4.14856

31. Biomechanical comparisons of knee stability after anterior cruciate ligament reconstruction between 2 clinically available transtibial procedures: anatomic double bundle versus single bundle Am J Sports Med. 2010 Jul; 38 (7):1349-58. doi: 10.1177/0363546510361234.

32. Siebold R, Dehler C, Ellert T. Prospective randomized comparison of double-bundle versus singlebundle anterior cruciate ligament reconstruction. Arthroscopy. 2008;24:137-145.

33. Van Eck CF, Lesniak BP, Schreiber VM, Fu FH. Anatomic single- and double-bundle anterior cruciate ligament reconstruction flowchart. Arthroscopy. 2010;26:258-268, Clin Orthop Relat Res. 2013 Feb; 471(2): 363-367, Published online 2012 Dec 14. doi: 10.1007/s11999-012-2737-1

34. Adachi N, Ochi M, Uchio Y, Iwasa J, Kuriwaka M, Ito Y. Reconstruction of the anterior cruciate ligament: single- versus double-bundle multistranded hamstring tendons. J Bone Joint Surg Br. 2004 May;86(4):515-20.
35. Kanaya A, Ochi M, Deie M, Adachi N, Nishimori $\mathrm{M}$, Nakamae A. Intraoperative evaluation of anteroposterior and rotational stabilities in anterior cruciate ligament reconstruction: lower femoral tunnel placed single-bundle versus double-bundle reconstruction. Knee Surg Sports Traumatol Arthrosc, Clin Orthop Relat Res. 2012 Mar; 470(3): 824-834, Published online 2011 Jun 11. doi: 10.1007/s11999011-1940-9

36. R. Siebold, T. P. Branch, H. I. Freedberg, C. A. Jacobs. A matched pairs comparison of single- versus double-bundle anterior cruciate ligament reconstructions, clinical results and manual laxity testing Knee Surg Sports Traumatol Arthroscopy, December 2011, Volume 19, Supplement 1, pp 4-11, doi.org/10.1007/s00167-011-1475-3

37. Eiji Kondo, Kazunori Yasuda, Hirotaka Azuma, Yoshie Tanabe and Tomonori Yagi Prospective Clinical Comparisons of Anatomic Double-Bundle Versus Single-Bundle Anterior Cruciate Ligament Reconstruction Procedures in 328 Consecutive Patients. Am J Sports Med 2008,36:1675. Volume:36 issue: 9, page(s): 1675-1687, doi.org/10. 1177/0363546508317123

38. Takeshi Muneta, Koga H, Morito T, Yagishita K, Sekiya I.. Retrospective Study of the Midterm Outcome of Two Bundle Anterior Cruciate Ligament Reconstruction Using Quadrupled Semitendinosus Tendon in Comparison With One-Bundle Reconstruction. Arthroscopy. 2006 Mar; 22(3): 252- 8. Volume 22, Issue 3, March 2006, Pages 252-258, doi.org/10.1016/j.arthro.2005.12.008

\section{How to cite this article?}

Thakur R., Samal N., Gawande V, Kochhal N. Clinical and functional evaluation of anterior cruciate ligament tears after anterior cruciate ligament reconstruction. Surgical Update: Int J surg Orthopedics.2019;5(1):33-40.doi:10.17511/ ijoso.2019.i01.06. 